Jerneja Novšak Brce

Damjana Kogovšek

Janez Jerman

Stanislav Košir

University of Ljubljana, Faculty of Education

\section{The Temperamental \\ Characteristic of Extraversion in Slovenian Preschool Children Who Stutter}

\begin{abstract}
Different authors agree that stuttering is a multifactorial disorder that manifests itself in verbal, psychological, physiological, physical and social fields and requires corresponding evaluation, diagnosis and treatment (Conture 2001; Logan, Yaruss, 1999; Vanryckeghem, Brutten, 1997; Zebrowski, Kelly, 2002). Contemporary research links the development of stuttering with certain temperamental characteristics, among which extraversion plays an important role. The aim of this study was to investigate one such temperamental characteristic - extraversion - in Slovenian preschool children who stutter and to compare these children with their fluently-speaking peers. Using a parent administered questionnaire (Inventory of Children's Individual Differences, Zupančič, Kavčič, 2009), extraversion as a temperamental characteristic was assessed in 49 children who stutter and in 75 children who do not stutter. All children were aged between 3 and 6 years.

The results demonstrated that preschool children who stutter achieved, on average, a statistically significantly lower score on the dimension of extraversion than preschool children who do not stutter. Accordingly, children who stutter are not as extraverted, active, sociable and open to experience as children who speak fluently.
\end{abstract}

Keywords: stuttering temperamental characteristics extraversion preschool children 


\section{INTRODUCTION}

Temperament refers to biologically based individual differences that are relatively stable over time and appears early in a child's development (e.g., Eggers et al., 2010; Goldsmith et al., 1987). As a dynamic factor, temperament "mediates and shapes the influence of the environment on the individual's psychological structure" (Goldsmith et al., 1987 , p. 509), and includes the "formal and stylistic features of behavior, such as the individual's sensitivity and responsivity to environmental demands" (Caprara and Cervone, 2000, p. 87).

Extraversion is a personal and temperamental dimension that measures sociability, enthusiasm and pleasurable arousal (Abe, 2005; Costa and McCrae, 1995; Hagekull and Bohlin, 1998; McCrae and Costa, 1987; McCrae and John, 1992). The facets included under this dimension are warmth, gregariousness, assertiveness, activity, excitement seeking and positive emotions. Individuals with high extraversion scores tend to be very active, outgoing, assertive, energetic, enthusiastic and talkative (Bumpass, 2009).

Recently, several researchers have considered the potential role of temperament in the onset and development of stuttering (Anderson et al., 2003; Conture, 2001; Guitar, 1998). Temperament differences may affect the susceptibility of individuals to learning processes and experiences. For instance, specific temperament traits, such as extraversion, make some individuals more susceptible to particular classical and operant conditioning processes (Gray, 1991), which are known to have an important role in the development of compensatory and other behaviours implicated in stuttering (Bloodstein, 1995; Brutten and Shoemaker, 1967; Kamhi, 2003; Eggers et al. 2010).

Extraversion as a personality trait is particularly important in connection to stuttering. It is one factor in the five-factor model of personality (Stipdonk, 2011), in which extraversion - introversion is a contrast based on sociability, excitability, dominance, assertiveness and emotional expressiveness. Extraverts are more assertive, active and talkative than introverts. They enjoy excitement, are positive-minded, energetic and optimistic. They are alert and focused on their environment. In contrast, introverts are detached, more independent and thoughtful and prefer being alone. They are more focused on their own feelings and thoughts than on their environment (Costa and McCrae, 1992). Thus, an introverted person may talk less than an extraverted person. In regards to stuttering, an introvert who stutters might stutter in a different manner than an extravert who stutters. Specifically, extraverts might stutter more overtly without shame or fear, while introverts may speak very thoughtfully and therefore try to avoid stuttering (Stipdonk, 2011).

Recently, theorists have suggested that children who stutter may possess more vulnerable or inherently sensitive temperaments (compared to their typically developing peers), which may contribute to their susceptibility to begin, continue or, conversely, to recover from stuttering (e.g., Anderson et al., 2003; Conture, 1991, 2001; Guitar, 1998; Zebrowski and Conture, 1998). Findings from published studies using several different methodologies have generally indicated that young children who stutter, when compared to children who do not stutter, are less successful in maintaining attention and adapting to their environment (Embrechts et al., 2000), are more reactive to environmental stimuli (Wakaba, 1998) and are more sensitive, anxious, introverted and withdrawn (Fowlie and Cooper, 1978; Glasner, 1949; Anderson et al., 2003).

In a study in which mothers were asked to describe their children using adjectives, Yairi (2007) found that children who stutter were described as insecure, sensitive, timid, fearful and introverted. In another study, Bharath and Ras (1970) used the Eysenck Personality Questionnaire to determine the personality characteristics of persons who stutter and found that people who stutter demonstrate a tendency towards neuroticism and introversion.

Klassen (2001) found that CWS (children who stutter) are more introverted and less confident. Similarly, Baz and Elsayed (2010) found that CWS achieve significantly lower scores on the dimension of extraversion than CWNS (children who do not stutter). In two older studies, Wakaba (1998) noted that CWS are more sensitive and introverted than CWNS and Fowlie and Cooper (1978) found that CWS are more introverted and reserved. On the other hand, Lewis and Goldberg (1997) observed a high adjustment capacity and a positive approach to new stimuli among CWS.

Guitar (1976) argues that personal or temperamental characteristics themselves are not predictors of the development of stuttering. His research has demonstrated that neither neuroticism nor extraversion, as measured using the Eysenck Personality Questionnaire, were themselves significant predictors of recovery from or persistence of stuttering. Instead, Guitar (1976) notes that a combination of these factors prior to thearpy (personal and temperamental characteristics, stuttering severity, communication attitude) is a useful predictor of successful treatment.

In a recent study, Bleek et al. (2012) investigated the association between the five-factor model of personality (measured using the NEO Five-Factor Inventory (NEOFFI)) and the Overall Assessment of the Speaker's Experience of Stuttering (OASES) in 112 adults of German nationality who stutter. Results revealed a strong positive correlation between the personality trait Neuroticism and scores on the OASES. Moreover, Extraversion was negatively correlated with the OASES scores. The authors also found that people with higher Neuroticism and lower Extraversion scores experience a greater impact of stuttering on their daily life (Bleek et al., 2012).

According to the findings of some authors (Anderson et al., 2003; Embrechts et al., 2000; Wakaba, 1998), preschoolers who stutter differ on the dimension of extraversion from preschool children who do not stutter. To date, studies examining these factors have been conducted using various measurement instruments. Use of the FiveFactor Model of personality has thus far only been used in studies with adult participants (Bleek et al., 2012). Using the Five-Factor Model, the present study is the first to examine differences on the dimension of extraversion among preschool children who stutter and their fluently-speaking peers.

The aim of this paper was to investigate the dimension of extraversion among Slovenian preschool children who stutter using the Inventory of Children's Individual 
Differences (ICID) and to determine whether differences on the five scales that constitute the dimension of extraversion exist among preschool children who stutter (CWS) and their peers who do not stutter (CWNS).

\section{METHODS}

\section{Participants}

The participants in this study were 49 preschool CWS (32 boys, 17 girls) and 74 preschool CWNS (39 boys, 35 girls) between the age of 3 and 6 years. The mean age was 55.01 months $(\mathrm{SD}=9.99)$ in the CWS group and 55.20 months $(\mathrm{SD}=9.92)$ in the CWNS group. CWS were recruited from three centers representing different urban and rural regions of Slovenia (Institute for the Deaf and Hard of Hearing in Ljubljana, the Center for Hearing and Speech in Maribor and the Center for Speech and Hearing in Portorož),. During the diagnostic phase, parents completed a historical form and children were assessed using the SSI-3 (Riley, 1994). For all children, the onset of stuttering occurred at least six months prior to the administration of the Inventory of Children's Individual Differences (ICID, Zupančič, Kavčič, 2009) and was observed during initial fluency assessment. None of the children had had prior treatment for stuttering or any other speech or language disorder.

CWNS were recruited from a number of nursery schools in Slovenia. Information about the absence of any speech, language, hearing, developmental or neurological disorders or a possible family history of stuttering was investigated by means of a parent survey and confirmed by the nursery school teacher and school records. All children were native Slovenian speakers.

\section{Variables}

The independent variables used to determine comparability between the CWS and CWNS groups were gender and age. The dependent variables were fluency (which is the criterion variable because it divides the sample into experimental and control groups) and items on the extraversion dimension.

\section{Materials}

The Inventory of Children's Individual Differences (ICID, Halverson et al., 2003) is an internationally designed measure of individual differences in children aged 3 to 12 years and is based on a child's personality lexicon from parental descriptions. In this investigation, the translated and adapted version published by $\mathrm{M}$. Zupančič and T. Kavčič (2009) was used. The ICID consists of 108 items in which mothers or fathers rat their child's characteristicsusing a $7-$ point scale. Together, the items form 15 scales, which in turn form 4 dimensions obtained by principal component analysis and Varimax rotation (Extraversion, Conscientiousness, Agreeableness and Neuroticism). The internal consistency estimates based on coefficient alpha for parental ratings on the ICID scales have been consistently high (between 0.71 and 0.92) (Zupančič and Kavčič, 2009). The dimension of extraversion consists of five scales: Positive Emotions (getting along well with others, happiness, cheerfulness); Sociability (outgoing, actively seeking company, desire to be with other people); Openness (tendency to explore, find out about things, ask a lot of questions); Considerate (being concerned about what happens to others, socially close, emphatic); and Activity Level (the level of energy output indicated by vigorous locomotion and being constantly on the move) (Zupančič and Kavčič, 2009).

\section{Procedure}

Written consent forms were collected from parents who agreed to their child's participation in the study. In order to evaluate their child's personailty characteristics, parents were asked to complete the ICID within a period of 10 days. Parents also provided answers to a few demographic questions (age and gender). Consistent with regulatory guidance regarding the application of psychodiagnostic resources,a psychologist was involved in the interpretation of all ICID results.

\section{RESULTS AND DISCUSSION}

On average, preschool CWS achieve lower scores on the dimension of extraversion $($ Mean $=23.50, S D=2.48)$ than preschool CWNS (Mean $=25.24, S D=3.25)($ Table 1$)$.

Table 1. Descriptive Statistics and t-test results for differences between CWS and CWNS on the Extraversion dimension

\begin{tabular}{|c|c|c|c|c|}
\hline $\begin{array}{l}\text { EXTRA- } \\
\text { VERSION }\end{array}$ & $\mathbf{N}$ & $\mathbf{M}$ & SD & $\begin{array}{l}\text { Levene's test: } \\
F=4,37 ; p=, 039 \\
\text { t-test: }\end{array}$ \\
\hline CWS & 49 & 23,50 & 2,48 & $\mathrm{t}=-3,38 ; \mathrm{p}=, 001$ \\
\hline CWNS & 75 & 25,24 & 3,25 & Effect size: $d=0,64$ \\
\hline
\end{tabular}

Legend:

CWS=children who stutter; CWNS=children who do not stutter; $\mathrm{N}=$ the number of the participants; $\mathrm{M}=$ mean; $\mathrm{SD}=$ standard deviation

A t-test (results are presented in Table 1) also demonstrated a statistically significant difference between preschool CWS and CWNS groups $(t=-3.38, p<0.001, d=$ 0.64), where CWS are less extraverted than CWNS. The effect size $(d>0.5)$ is medium.

In the present study, we also wished to determine on which of the five scales of the extraversion dimension (Activity Level, Sociability, Openness, Positive Emotions, and Considerate) were the differences between CWS and CWNS found.

As can be seen in Table 2, differences between groups of preschool CWS and CWNS are not statistically significant 
on the "positive emotions" $(t=-1.68, p=0.102, d=0.31)$ and "considerate" ( $t=-0.67, p=0.504, d=0.12)$ scales, suggesting that preschool CWS and CWNS do not vary in their positive emotions (affection for others, happiness, cheerfulness) and level of consideration (sensitivity, ability to empathize, help or stand up for someone, ability to go easy on someone). The effect size (d) on both "positive emotions" and "considerate" scales is similarly small.

Table 2. Descriptive Statistics and t-test results for particular scales of the Extraversion dimension for CWS and CWNS groups

\begin{tabular}{|c|c|c|c|c|c|}
\hline & & $\mathbf{N}$ & $\mathbf{M}$ & SD & \\
\hline \multirow{3}{*}{$\begin{array}{l}\text { Activity } \\
\text { Level }\end{array}$} & CWS & 49 & 4,65 & 0,69 & \multirow{3}{*}{$\begin{array}{l}\text { Levene's test: } \\
F=3,24 ; p=0,074 \\
\text { t-test: } \\
\text { t=-3,58; } p=0,000 \\
\text { Effect size: } \\
d=0,67\end{array}$} \\
\hline & & & & & \\
\hline & CWNS & 75 & 5,17 & 0,86 & \\
\hline \multirow{3}{*}{ Sociability } & CWS & 49 & 4,46 & 0,69 & \multirow{3}{*}{$\begin{array}{l}\text { Levene's test: } \\
F=1,64 ; p=0,202 \\
\text { t-test: } \\
t=-2,93 ; p=0,004 \\
\text { Effect size: } \\
d=0,55\end{array}$} \\
\hline & & & & & \\
\hline & CWNS & 75 & 4,87 & 0,79 & \\
\hline \multirow{3}{*}{ Openness } & CWS & 49 & 4,40 & 0,51 & \multirow{3}{*}{$\begin{array}{l}\text { Levene's test: } \\
F=1,27 ; p=0,263 \\
\text { t-test: } \\
\text { t=-4,64; } p=0,000 \\
\text { Effect size: } \\
d=0,87\end{array}$} \\
\hline & & & & & \\
\hline & CWNS & 75 & 4,88 & 0,59 & \\
\hline \multirow{3}{*}{$\begin{array}{l}\text { Positive } \\
\text { Emotions }\end{array}$} & CWS & 49 & 4,96 & 0,73 & \multirow{3}{*}{$\begin{array}{l}\text { Levene's test: } \\
F=1,13 ; p=0,290 \\
\text { t-test: } \\
t=-1,68 ; p=0,102 \\
\text { Effect size: } \\
d=0,31\end{array}$} \\
\hline & & & & & \\
\hline & CWNS & 75 & 5,20 & 0,80 & \\
\hline \multirow{3}{*}{ Considerate } & CWS & 49 & 5,09 & 0,74 & \multirow{2}{*}{$\begin{array}{l}\text { Levene's test: } \\
F=1,01 ; p=0,296 \\
\text { t-test: } \\
t=-0,67 ; p=0,504\end{array}$} \\
\hline & & & & & \\
\hline & CWNS & 75 & 5,12 & 0,86 & $\begin{array}{l}\text { Effect size: } \\
d=0,12\end{array}$ \\
\hline
\end{tabular}

Legend:

CWS=children who stutter; CWNS=children who do not stutter; $\mathrm{N}=$ the number of the participants; $\mathrm{M}=$ mean; $\mathrm{SD}=$ standard deviation

However, one item proved to be statistically significant on both "positive emotions" and "considerate" scales: 'warmth' ( $t=-2.36, p=0.020, d=0.43)$. Here, the effect ( $d$ $<0.50)$ is small. On this item, CWS achieved statistically significantly lower scores than CWNS. It might be suggested that, because pleasantness is often associated with appearance and the manner of speech, parents of CWS consider their children less adorable. Arguably, CWS are externally marked as a result of their stuttering disorder, where outwardly visible stuttering makes a strong first impression on other people.

On the "positive emotions" scale, a statistically significant difference between CWS and CWNS groups was also found on the item 'is well understood by the others' ( $t$ $=-2.34, p=0.021, d=0.44)$, where CWS are significantly less understood by others. Indeed, as a result of negative experiences in connection with their own speech, CWS can become a target for teasing and exclusion. This finding might also indicate that parents of CWS estimate that their children do not get along with others, have fewer friends or are more socially isolated.

Statistically significant differences between CWS and CWNS groups were also found on the "activity level" $(t=$ 3.58, $p<0.001, d=0.67)$, "'sociability" $(t=-2.93, p=0.004$, $d=0.55)$, and "openness" $(t=-4.64, p<0.001, d=0.87)$ scales. In the opinion of their parents, CWS are significantly less active (physical activity, tendency to move or to deal with something), less social (tendency to socialize, search for contacts with others) and less open to experience (tendency to explore, show interest in people, events or situations) than CWNS.

On the "activity level" scale, all items were significantly different between CWS and CWNS groups, with the exception of items assessing "vigor" $(t=-0.23, p=0.818$, $d$ $=0.05)$. Specifically, CWS achieved statistically significantly lower scores on items assessing activity, movement and outdoor play, suggesting that CWS are less physically active and, in comparison to fluent speakers, play less outdoors or engage in fewer outdoor activities. While parents likely assessed this movement and activity as sports activity rather than movement as a motoric disorder, some authors (Howell et al., 2004) note that this form of motoric disorder is more prevalent among CWS. Arguably, this difference in motoric activity and a reduced desire for outdoor games might be connected to social influences, where the majority of childhood physical activities are not individual but rather involve play with peers. If a child is exposed due to the way he or she speaks and if peers tease the child because of his or her speech, it seems reasonable that this child might prefer avoiding such activities and rather spend time reading, watching television or engaged in other activities in which it is not necessary to expose one's speech and do not depend on other children.

On the "sociability" scale, a statistically significant difference between CWS and CWNS groups is also evident, where CWS achieve lower scores, on average, on all scale items. Specfiically, statistically significant differences between groups was found on 'sociability' $(t=-1.94, p=$ $0.055, d=0.35)$, 'adaptability' $(t=-2.99, p=0.003, d=0.55)$ and "socializing" ( $t=-2.44, p=0.016, d=0.45)$ items, as well as on the "number of friends" item $(t=-2.84, p=$ $0.005, d=0.51)$. According to parents, CWS find company among a significantly smaller number of peers, have difficulty adpating to new situations, do not like being in social situations and do not have a large number of friends. These results correspond with the findings of a number of other studies (Anderson et al., 2003; Embrechts et al., 2000; Howell et al., 2004) and suggest that CWS are less adaptable 
to new situations and need more time to adapt to new events, people and circumstances than CWNS. To date, this is the only personality trait that has proven to be statistically significant in any research. Our argument that CWS, because of the way they speak, do not seek the company of their peers and do not have as many friends as CWNS is conistent with that of Anderson and others (2003), who recognized that CWS are less eager to seek the company of their peers, prefer to maintain current contacts rather than enter into new ones, and communicate with others less frequently and for a shorter period of time. Together, these factors contribute to less frequent communication and fewer opportunities for feedback, which is especially important for children's development in the preschool period.

The "openness" scale also indicates statistically significant differences between preschool CWS and CWNS. In Table 2, which presents average scores on the scales for all extraversion dimensions, it is evident that CWS achieved lower scores than CWNS on the "openness" scale. In contrast, CWS do not statistically significantly differ from CWNS on items that evaluate level of creativity $(t=-1.19, p$ $=0.236, d=0.22)$ or imagination $(t=-0.53, p=0.599, d=$ $0.10)$ and the degree to which they accept new ideas $(t=$ $0.41, p=0.681, d=0.08)$. A child who stutters can relax and perform well in activities that do not pose a need for speech exertion. Creativity and imagination, where CWS do not differ from CWNS, definitely belong in this category. More surprising is the finding that there is no significant difference between groups for the item 'difficulties with accepting new ideas' $(t=0.41, p=0.681, d=0.08)$. While the average score on items examining acceptance of new ideas is higher among CWS, this difference is not statistically significant. As previously mentioned, a number of researchers (Anderson et al., 2003; Embrechts et al., 2000; Howell et al., 2004) have found that CWS appear to be slower in adapting to novelty than CWNS. In the present study, the lack of statistically significant difference on this item might suggest that parents assessed their children in very narrow terms of acceptance of new ideas (and not a wider understanding related to adapting to change). On the "openness" scale, statistically significant differences were also found on the 'talkativeness' $(t=-3.87$, $p<0.001, d=0.70)$ and "questioning" $(t=-4.82, p<0.001$, $d=0.89)$ items. This finding might suggest that, as a result of negative experiences during speech, CWS are more likely to avoid speech and are tense and uneasy in situations requiring speech. Furthermore, it follows that parents and others might estimate that CWS show less interest in things around them than CWNS. Indeed, on the item "interest in things around him or her", there was also a statistically significant difference between the CWS and CWNS groups $(t=-3.11, p=0.002, d=0.57)$. A statistically significant difference was also found on the item evaluating "sense of humour" ( $t=-2.70, p=0.008, d=0.51)$, suggesting that even humour can be associated with speech and, as such, parents estimated that CWS demonstrated less sense of humour than CWNS.

Together, the findings examining differences in the dimension of extraversion indicate that CWS achieved significantly lower results than CWNS. When specific scales within the extraversion dimension were conisdered, statistically significant differences between CWS and CWNS were observed on the "activity level", "sociability" and "openness" scales.
Although previous research examining temperamental and personal characteristics of preschool CWS has produced contradictory results, the findings from a number of studies from various authors have consistently demonstrated that CWS differ from CWNS on the dimensions of extraversion (Baz and Elsayed, 2010; Klassen, 2001; Lewis and Goldberg, 1997; Stipdonk, 2011; Wakaba, 1998).

\section{CONCLUSIONS}

Recent studies (Eggers et al., 2010; Stipdonk, 2011) examining stuttering have demonstrated that the phenomenon of stuttering is associated with various temperamental and personal characteristics. Because stuttering usually occurs between the ages of 3 and 5 years and the success of therapy is higher in early stages of life, the preschool period is especially crucial for children who stutter. For this reason, information about the temperamental characteristics of an individual is important for effective therapy.

On all scales of the extraversion dimension, preschool CWS achieved, on average, lower scores than preschool CWNS. Differences between groups were statistically significant on the "activity level", "sociability" and "openness" scales, suggesting that preschool CWS are less physically active, show less tendency to move, are less sociable, do not seek contact with others and are less open to experience, less prone to exploring and show less interest in people, events and situations. Differences between groups were not statistically significant on the "positive emotions" and "considerate" scales, indicating that preschool CWS and preschool CWNS do not differ on the following items: affection toward others, satisfaction, playfulness and sensibility, the ability to empathize, to help, to stand up for someone and to be lenient. These findings are consistent with those from other well-known researchers that similarly found differences in the dimensions of extraversion among preschool CWS and CWNS (Baz and Elsayed, 2010; Bharath and Ras, 1970; Fowlie and Cooper, 1978; Klassen, 2001; Wakaba, 1998).

As such, the results of our research are, to a large extent,similar to those from other similar studies. However, these studies have further demonstrated differences on different temperamental characteristics. A possible explanation for this discrepancy might be found in the different approaches used for collecting data, which range from questionnaires, interviews, free descriptions, observations at home and under laboratory conditions to monitoring various psychophysical and psychophysiological indicators as well as the combined use of different approaches. We agree with Guitar's (1976) findings, who argues that, although personal and temperamental characteristics itself are not a predictor of the development of stuttering, they are certainly an important factor. According to Guitar (1976), the combination of personal and temperamental characteristics, stuttering severity and communication attitude is an important factor that influences the success of therapy and stuttering recovery. In future research, it would be important to examine the personal and temperamental characteristics of children who recover from stuttering and to compare these characteristics 
with those of children whose stuttering persists.

The data used in the present study were provided by parents, thus raising a question of the validity and reliability of parents' ratings. Indeed, while scientific studies have not confirmed certain traits among children who stutter, the interpretation of the results in the present study established a significant degree of stereotypical thinking about CWS among parents. The results of previous research with preschool children in Slovenian kindergartens (Zupančič and Kavčič, 2009) suggest that parent ratings are consistent within a single environment (i.e. family - mother, father), where Pearson's $\mathrm{r}$ is greater than 0.60. Because the agreement between ratings for a single child across reviewers from different environments (e.g. mother - teacher) is much lower (Pearson's $r$ is 0.30), it would be interesting to include preschool teachers in future research. It would be similarly interesting to examine whether differences among children who stutter occur on the same items in the ratings of parents and preschool teachers and if stereotypical beliefs about children who stutter (less warm, less intelligent ...) are even more prevalent among preschool teachers. Finally, in light of the conflicting data regarding the characteristics of children who stutter and the impact of stereotypes in the evaluation of these characteristics, it would be useful to consider alternative methods to examine personal and temperamental characteristics.

\section{REFERENCES}

1) Abe, J. A. (2005). The predictive validity of the fivefactor model of personality with preschool age children: A nine year follow-up study. Journal of Research in Personality, 39 , 423-442.

2) Anderson, J., Pellowski, M., Conture, E., Kelly, E. (2003). Temperamental characteristics of young children who stutter. Journal of Speech, Language, \& Hearing Research, 46, 1221-1233.

3) Baz, H., Elsayed, H. (2010). Psychosocial Profile of Preschool Stuttering Children with Co-morbid Psychiatric Disorders. Unit of Phoniatrics, Faculty of Medicine, Mansoura University, Mansoura, Egypt.

4) Bharath, R., Ras, B. (1970). Personality characteristics of stutteres. Journal of All India Institute of Speech and Hearing, 1, 7-13.

5) Bleek, B., Reuter, M., Yaruss, S. J., Cook, S., Faber, J., Montag, C. (2012). Relationship between personality characteristics of people who stutter and the impact of stuttering on everyday life. Journal of Fluency Disorders 37, 325-333.

6) Bumpass, C. R. (2009). Personality and curiosity in preschool children. Graduate School of Western Carolina University.

7) Caprara, G., Cervone, D. (2000). Personality: Determinants, dynamics and potentials. Cambridge: University Press.

8) Conture, E. G. (1991). Young stutterer's speech production: A critical review. In: H. Peters, W. Hulstijn, C. Starkweather (Ed.), Speech motor control and stuttering. Amsterdam: Elsevier Science Publishers.

9) Conture, E. G. (2001). Stuttering: Its nature, diagnosis and treatment. Boston: Allyn \& Bacon.

10) Costa, P. T., McCrae, R. R. (1992). Revised NEO Personality Inventory (NEO-PI-R) and the Five Factor Inventory
(NEO-FFI): Professional manual. Odessa, Florida: Psychological Assessment Resources Inc.

11) Costa, P. T., McCrae, R. R. (1995). Domains and facets: Hierarchical personality assessment using the revised NEO personality inventory. Journal of Personality Assessment, 64, 2150.

12) Eggers, K., DeNil, L. F., Van den Bergh, B. R. H. (2010). Temperament dimensions in stuttering and typically developing children. Journal of Fluency Disorders, 35, 1-18.

13) Embrechts, M., Ebben, H., Franke, P., van de Poel, C. (2000). Temperament: A comparison between children who stutter and children who do not stutter. In: Bosshardt, $\mathrm{H}$. G.; Yaruss, J. S.; Peters, H. F. M., (Ed.): Proceedings of the Third World Congress on Fluency Disorders: Theory, research, treatment, and self-help (p. 557-562). University of Nijmegen Press; Nijmegen, The Netherlands.

14) Fowlie, G. M., Cooper, E. B. (1978). Traits attributed to stuttering and nonstuttering children by their mothers. Journal of Fluency Disorders, 3, 233-246.

15) Goldsmith, H., Buss, A., Plomin, R., Rothbart, M., Thomas, A., Chess, S., et al. (1987). Roundtable: What is temperament? Four approaches. Child Development, 58, 505529.

16) Gray, J. A. (1991). The neuropsychology of temperament. In: A. Angleitner, \& J. Strelau (Ed.), Explorations in temperament: International perspectives on theory and measurement. New York: Plenum.

17) Guitar, B. (1976). Pretreatment factors associated with the outcome of stuttering therapy. Journal of Speech and Hearing Research, 19, 590-600.

18) Guitar, B. (1998). Stuttering: An integrated approach to its nature and treatment. Baltimore: Williams \& Wilkins.

19) Hagekull, B., Bohlin, G. (1998). Preschool temperament and environmental factors related to the five-factor model of personality in middle childhood. Merrill-Palmer Quarterly, 44, 194-215.

20) Halverson, C. F., Jr., Havill, V. L., Deal, J., Baker, S. R., Victor, B. J., Pavlopoulos, V., Besevegis, E., Wen, L. (2003). Personality structure as derived from parental ratings of free descriptions of children: The Inventory of Child Individual Differences. Journal of Personality, 71, 995-1026.

21) Howell, P., Davis, S., Patel, H., Cuniffe, P., DowningWilson, D., Au-Yeung, J.,Williams, R. (2004). Fluency development and temperament in fluent children and children who stutter. In: Packman A., Meltzer A., Peters H. F.M. (Ed.), Theory, research and therapy in fluency disorders. Proceedings of the 4th World Congress on Fluency Disorders (p. 250256).

Klassen, T. R. (2001). "The complexity of attitudes toward people who stutter," Proceedings of the Third World Congress on Fluency Disorders. Nijmegen, Netherlands: Nijmegen University Press, 605-609.

22) Lewis, K. E, Goldberg, L. L. (1997). Measurements of temperament in the identification of children who stutter. European Journal of Disorders of Communication, 32, 441-448.

23) Logan, K., Yaruss, S. (1999). Helping parents address attitude and emotional factors with young children who stutter. Contemporary Issues in Communication Sciences and Disorders, 26, 69-81.

24) McCrae, R. R., Costa, P. T., (1987). Validation of the Five-Factor Model of personality across instruments and observers. Journal of Personality and Social Psychology, 52, 81-90. 25) McCrae, R. R., John, O. P. (1992). An introduction to 
the five-factor model and its applications. Journal of Personality, 60, 175-215.

26) Riley, G. D. B. (1994). Stuttering Severity Instrument for Children and Adults. Third edition. Austin: Pro-ed.

27) Stipdonk, L. (2011). Personality Influences in Stuttering

- The influence of extraversion on type of dysfluency and communication attitude. Universiteit Utrecht, Opleiding MSc Logopediewetenschap Clinical Language, Speech, and Hearing Sciences. Master Thesis.

28) Vanryckeghem, M., Brutten, G. (1997). The speechassociated attitude of children who do and do not stutter and the differential effect of age. American Journal of SpeechLanguage Pathology, 6, 67-73.

29) Wakaba, Y. (1998). Research on temperament of children who stutter with early onset. In: Healey, E. C., Peters, H. F. M., (Ed.): Stuttering: Proceedings of the Second World Congress on Fluency Disorders (str. 84-87). University Press Nijmegen; Nijmegen, The Netherlands.

30) Yairi, E. (2007). Subtyping stuttering I: A review. Journal of Fluency Disorders, 32, 165-196.

31) Zebrowski, P., Conture, E. (1998). Influence of nontreatment variables on treatment effectiveness for schoolage children who stutter. In A. Cordes, \& R. Ingham (Ed.), Treatment efficacy for stuttering: A search for empirical bases. San Diego: Singular Publishing Group.

32) Zebrowski, P., Kelly, E. (2002). Manual of stuttering intervention. Singular Thomson Learning. Clifton Park: NewYork.

33) Zupančič, M., Kavčič, T. (2009). Vprašalnik o medosebnih razlikah pri otrocih in mladostnikih. Ljubljana: Center za psihodiagnostična sredstva. 